\title{
NEUROPHYSIOLOGY IN THE ASSESSMENT OF THE EFFICACY OF THE REHABILITATION OF SENSOMOTOR DISTURBANCES DUE TO SPINAL CORD LESIONS
}

\author{
Evgeniya Ekusheva ${ }^{1,2}$, Vladislav Voitenkov ${ }^{3}$, Natalia Skripchenko ${ }^{3}$, Irina Samoilova ${ }^{3}$, Elena Kiparisova ${ }^{2}$ \\ ${ }^{1}$ Scientific Research Department of Neurology, I.M. Sechenov First Moscow State Medical University, \\ 119991, Moscow, Russia. \\ ${ }^{2}$ Advanced Training Institute of the Federal Medical Biological Agency, 125371, Moscow, Russia. \\ ${ }^{3}$ Pediatric Research and Clinical Center for Infectious Diseases, 127022, St-Petersburg, Russia.
}

Introduction: due to costs and length of neurorehabilitation treatment, objective evaluation of its efficacy is important.

Purpose: our aim was to assess and compare efficacy of differentiated methods of neurorehabilitation of somatosensory disturbances in patients with spinal cord lesions.

Method: 68 patients with spinal cord lesions were enrolled: 38 with vascular myelopathy, 18 with extramedullar meningioma surgery sequelae, 12 with sequelae of acute transverse myelitis. There were 55 controls. All patients underwent rehabilitation which included robotized mechanotherapy, stabilography, neuro-muscular stimulation, kinesiotherapy, physical therapy, ergotherapy, massage etc. Before and after the therapy TMS and SSEP parameters were evaluated in all patients using magnetic stimulator Neiro-MS-D and NeiroMVP-8 EMG, NCS and EP system.

Results: In those patients who received personalized therapy significant changes of TMS parameters (central motor conduction time at rest and in facilitation probe) (see Table 1), but not SSEP ones were registered. In those who underwent personalized therapy better clinical results were seen.

Discussion and conclusions: Thus, neurorehabilitation was more effective in treatment of motor disturbances; sensory were more resistant to therapy. Our data suggests

that taking into the account of the sensory deficit have to be mandatory in neurorehabilitation planning. TMS and SSEP have to be utilized for the objective evaluation of the central part of the nervous system in spinal cord lesions rehabilitation.

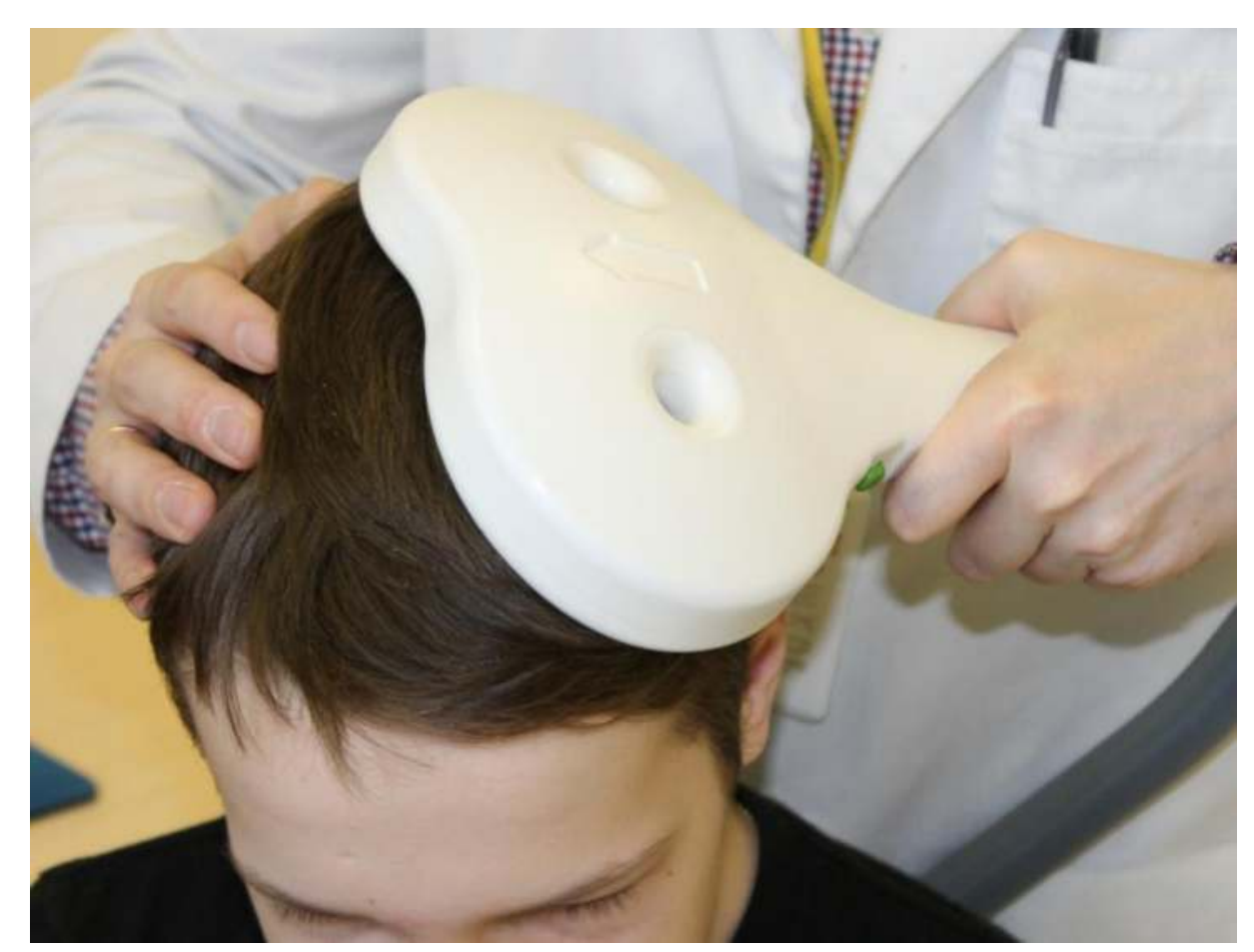

Table 1. MEP parameters in groups before and after the rehabilitation and in controls

\begin{tabular}{|c|c|c|c|c|c|}
\hline \multirow{3}{*}{ MEPs parameters } & \multicolumn{4}{|c|}{ Patients with spinal cord lesions } & \multirow{3}{*}{$\begin{array}{c}\text { Controls } \\
(n=55)\end{array}$} \\
\hline & \multicolumn{2}{|c|}{ Group $1(n=32)$} & \multicolumn{2}{|c|}{ Group $2(n=36)$} & \\
\hline & $\begin{array}{c}\text { Before } \\
\text { treatment }\end{array}$ & $\begin{array}{c}\text { After } \\
\text { treatment }\end{array}$ & $\begin{array}{c}\text { Before } \\
\text { treatment }\end{array}$ & $\begin{array}{c}\text { After } \\
\text { treatment }\end{array}$ & \\
\hline $\mathrm{CMCT}, \mathrm{ms}$ & $22,3 \pm 5,3^{*}$ & $20,9 \pm 5,5^{*}$ & $23,3 \pm 6,1^{*}$ & $19,1 \pm 5,1^{*}$ & $17,4 \pm 2,3$ \\
\hline $\begin{array}{l}\text { Facilitated CMCT, } \\
\mathrm{ms}\end{array}$ & $18,5 \pm 6,3^{*}$ & $18,3 \pm 6,3^{*}$ & $18,3 \pm 6,3^{*}$ & $\begin{array}{l}14,4 \pm 5,2^{\circ} \\
\#\end{array}$ & $13,2 \pm 2,4$ \\
\hline $\begin{array}{l}\text { MEPs resting } \\
\text { threshold, \% }\end{array}$ & $71,6 \pm 7,3^{*}$ & $72,8 \pm 8,6^{*}$ & $74,8 \pm 8,4^{*}$ & $71,7 \pm 7,2^{*}$ & $65,8 \pm 8,2$ \\
\hline $\begin{array}{l}\text { Facilitated MEPs } \\
\text { resting threshold, \% }\end{array}$ & $64,3 \pm 7,2^{*}$ & $63,5 \pm 6,3^{*}$ & $63,9 \pm 6,2^{*}$ & $\begin{array}{c}56,4 \pm 5,1^{\circ} \\
\#\end{array}$ & $53,7 \pm 7,3$ \\
\hline
\end{tabular}

- significant differences between patients and controls $(p<0,05) ; \cdot$ - significant differences between parameters in Group 2 patients before and after the treatment $(p<0,05) ; \#$ - significant differences between parameters in Group 2 and 1 patients after the treatment $(p<0,05)$.
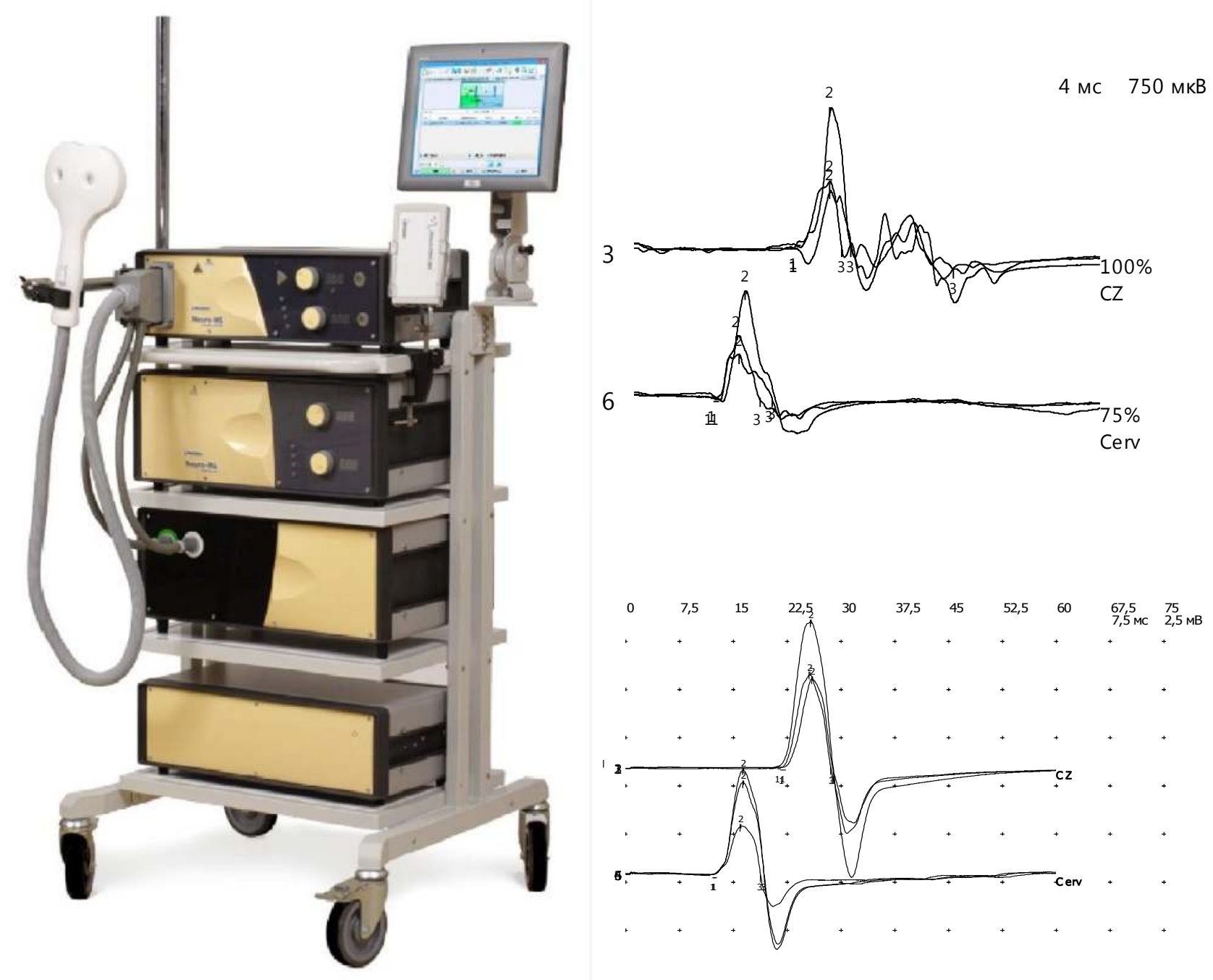